\title{
A Mixture of Glycosylated proBNP and BNP-32 Is a Suitable Calibrator for BNP Immunoassays
}

\author{
Keiichi Masuta1 ${ }^{*}$, Kenzo Funatsuki1, Youko Inoue ${ }^{1}$, Izuru Masuda ${ }^{2}$, Toshio Nishikimi3 ${ }^{3,4}$, \\ Yasuaki Nakagawa ${ }^{3}$, Kazukiyo Horii ${ }^{5}$, Hiroshi Nishi ${ }^{1}$, Masayo Igarashi ${ }^{1}$, Norio Ota ${ }^{1}$ \\ ${ }^{1}$ Biomarker R \& D Department, Shionogi \& Co., Ltd., Toyonaka, Japan \\ ${ }^{2}$ Takeda Hospital Medical Examination Center, Kyoto, Japan \\ ${ }^{3}$ Department of Cardiovascular Medicine, Kyoto University Graduate School of Medicine, Kyoto, Japan \\ ${ }^{4}$ Department of Medicine, Wakakusa-Tatsuma Rehabilitation Hospital, Daito, Japan \\ ${ }^{5}$ Horii Planning, Yokohama, Japan \\ Email: ${ }^{\star}$ keiichi.masuta@shionogi.co.jp
}

How to cite this paper: Masuta, K., Funatsuki, K., Inoue, Y., Masuda, I., Nishikimi, T., Nakagawa, Y., Horii, K., Nishi, H., Igarashi, M. and Ota, N. (2019) A Mixture of Glycosylated proBNP and BNP-32 Is a Suitable Calibrator for BNP Immunoassays. Open Journal of Clinical Diagnostics, 9, 51-63.

https://doi.org/10.4236/ojcd.2019.92004

Received: April 21, 2019

Accepted: June 26, 2019

Published: June 29, 2019

Copyright $\odot 2019$ by author(s) and Scientific Research Publishing Inc. This work is licensed under the Creative Commons Attribution International License (CC BY 4.0).

http://creativecommons.org/licenses/by/4.0/ (c) (i) Open Access

\begin{abstract}
Aim: Measurement of B-type natriuretic peptide (BNP) is widely used as a diagnostic and risk assessment tool for cardiovascular disease. Recent studies have demonstrated that BNP-32 and its precursor proBNP circulate in the blood stream, and that most commercial BNP immunoassays measure both forms. However, recombinant or synthetic BNP-32 is used as the standard for those BNP immunoassays. This gap between clinical samples and the standard might be a potential source of variation in BNP measurements among assays. The purpose of this study is to validate a more suitable calibrator for BNP immunoassays. Methods: External BNP calibrators containing both BNP-32 and glycosylated proBNP were prepared at two concentration levels. Target BNP concentrations of the low and high levels were 40 and $160 \mathrm{pg} / \mathrm{mL}$, respectively. And to reflect clinical samples, the molar ratios of BNP-32 to glycosylated proBNP in these concentration levels were adjusted to 50:50 and 25:75, respectively. BNP concentrations of plasma samples along with the external BNP calibrators were measured at two commercial labs and using an automated analyzer MI02 Shionogi ${ }^{\oplus}$ BNP (MI02). These samples and the calibrators were also measured using an immunoradiometric assay (IRMA) as a standard assay procedure. Concentrations of the plasma samples measured at the labs or using the MI02 were adjusted according to a comparison of the measured concentrations of the external BNP calibrators with the IRMA. Results: After measured concentrations of the plasma samples were adjusted using the external BNP calibrators, the correlation between each measurement and the IRMA was improved. The range of the slopes according to Passing-Bablok regression analysis narrowed from 0.628 - 0.955 to 0.911 1.005. Conclusions: Our data suggests that a mixture of BNP-32 and glyco-
\end{abstract}


sylated proBNP at different ratios by concentration level is suitable for calibration to minimize variations in BNP measurements among immunoassays.

\section{Keywords}

B-Type Natriuretic Peptide (BNP), proBNP, Calibrator

\section{Introduction}

B-type natriuretic peptide (BNP) is a 32 amino acid peptide hormone produced by myocardium [1] [2]. The expression and secretion of BNP increase significantly in response to pressure overload, volume overload, and ischemic injury with heart failure (HF) and myocardial infarction [3].

In the last few decades, BNP has been successfully developed as a biomarker for various life sciences. In cardiovascular and related fields, BNP has become an indispensable biomarker in clinical practice along with troponins. For instance, screening BNP concentrations can establish risk for patients bearing symptoms that imply HF. Additionally, various trials have established the use of BNP measurements for other diagnoses and treatments including dyspnea, cardiogenic brain embolism, and general medical wellness [4] [5]. Therefore, clinical guidelines recommend measuring BNP to aid in the diagnosis of HF and other diseases and to monitor disease progression [6] [7].

The BNP gene encodes a 134 amino acid preproBNP precursor that includes a 26 amino acid signal peptide [1]. After the signal peptide is cleaved, a 108 amino acid BNP precursor peptide (proBNP) is generated, and further processing of proBNP gives two fragments, NT-proBNP (amino acids 1 - 76) and BNP-32 (amino acids 77 - 108) [8]. Some gel filtration studies have shown the presence of two BNP immunoreactive fractions of high-molecular-weight (MW) (30 - 40 $\mathrm{kDa})$ and low-MW $(\sim 3 \mathrm{kDa})$, which correspond to proBNP and BNP-32, respectively [8] [9] [10]. Moreover, Giuliani et al. developed a proBNP specific immunoassay and confirmed the presence of proBNP in the blood [11]. Some studies have shown that proBNP is the major form in blood from patients with HF [12] [13]. Recently, we reported on the molecular forms of BNP and its analogues in regard to HF severity related to the ratio of BNP-32 to proBNP [14].

Schellemberger et al. reported that proBNP is an O-glycosylated protein with seven identified glycosylation sites [15]. Recently, another study has described 9 glycosylation sites on circulating proBNP in HF patients [16]. All glycosylation sites are located on the NT-proBNP part of proBNP, and the glycosylation status of one amino acid, T71, is crucial for processing proBNP into NT-proBNP and BNP-32 due to the distance between the O-glycosylation and cleavage site [17] [18] [19]. These findings suggest that proBNP in circulation is O-glycosylated, including at amino acid T71, which is nearest to the cleavage site. Figure 1 depicts the mechanism of the formation of proBNP, BNP-32, and NT-proBNP in circulation. 


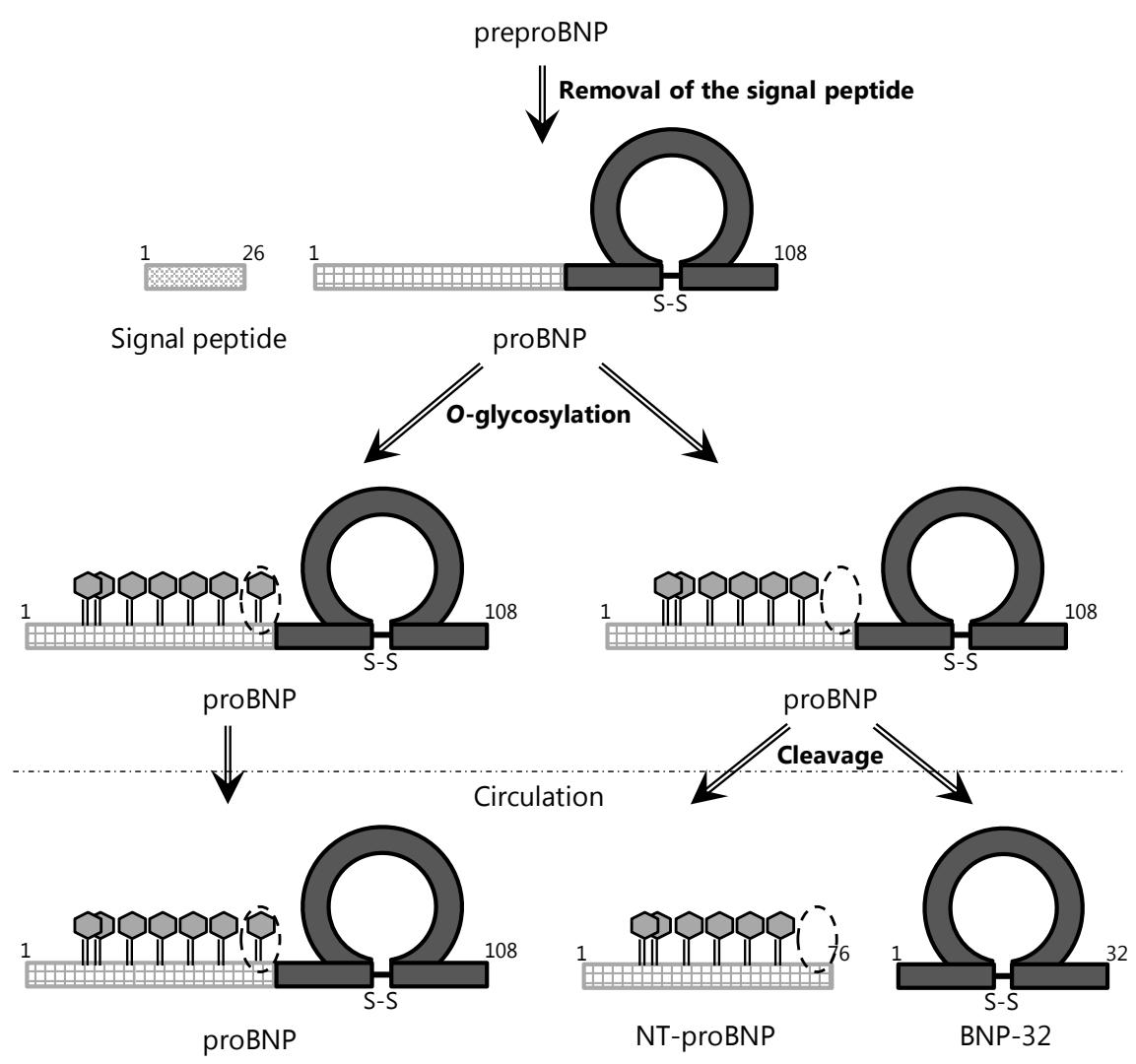

Figure 1. Scheme of proBNP processing. After proBNP is formed, O-glycosylation occurs at several sites (glycans on proBNP are indicated by hexagons). Only proBNP that is not glycosylated at T71 can be processed to BNP-32 and NT-proBNP. This figure was modified based on the figure shown in [18].

As shown in several reports [20] [21] [22], the BNP measurement reagents that are commercially available simply provide the total BNP or sum of proBNP (the majority is glycosylated proBNP as described above) and BNP-32, while not being able to measure the respective contents due to the sandwich immunoassay system. And it should be noted that cross-reactivities to the glycosylated proBNP are different among assays [23]. However, recombinant or synthetic BNP-32 is used as standard material for almost all commercially available BNP immunoassays. These differences in cross-reactivity and the gap between the existence of BNP-derived peptides in clinical samples and in standards might cause variability in BNP measurement results with different BNP assays.

To monitor the history of BNP concentrations in the same patient, which are often measured in different places using different BNP assays, it is desirable that the assays be comparable. Currently, there is no primary reference material for BNP measurement. Therefore, we developed a common calibrator as a primary reference material. The new calibrator is comprised of proBNP and BNP-32 corresponding to the various total BNP concentrations that indicate the severity of HF. Our new calibration method for measuring total BNP can improve clinical decision-making. 


\section{Methods}

\subsection{Ethics}

This study was approved by the Ethics Committee of Takeda Hospital Group (approval No. 1508) and the Shionogi Human Research Ethics Committee (approval No. HSI 15-023), and written informed consent was obtained from all subjects.

\subsection{Measurement of proBNP and Total BNP in Clinical Samples}

Blood samples were collected into $7 \mathrm{~mL}$ of PET (polyethylene terephthalate) tubes (two tubes each) containing $1.5 \mathrm{mg} / \mathrm{mL}$ of EDTA-2Na (ethylenediaminetetraacetic acid disodium salt) from 60 subjects ( 31 males, aged 48 to 95 years (average 76.9 years)). The subjects were selected from patients treated at Takeda Hospital or Koseikai Clinic, who was diagnosed as heart failure or its suspicion. Plasma was separated from the blood, and aliquots of the plasma were stored below $-70^{\circ} \mathrm{C}$ before measurements. BNP concentrations of the plasma samples were measured using a traditional immunoradiometric assay (IRMA) long in use [24] [25]. We prepared the IRMA reagent according to an established protocol. In addition, plasma total BNP and proBNP were also measured using recently developed chemiluminescent enzyme immunoassays (CLEIA) [26]. The assay for total BNP uses antibodies that recognize the $\mathrm{C}$-terminus and ring region of $\mathrm{BNP}$, respectively. Therefore, this assay detects both proBNP and BNP-32. In contrast, the assay specific to proBNP uses an antibody that recognizes the $\mathrm{N}$-terminus (amino acids 13 - 20) of proBNP instead of the ring antibody used for the total BNP assay.

\subsection{Preparation of External BNP Calibrators}

External BNP calibrators were prepared as follows: 1) anti-BNP monoclonal antibody specific to the ring region of BNP was immobilized on polystyrene beads (Immunochemical, Okayama, Japan); 2) the antibody beads were added into pooled normal human plasma (Tennessee Blood Service, TN, USA) and incubated for $18 \mathrm{~h}$ at $2^{\circ} \mathrm{C}-8^{\circ} \mathrm{C}$ with gentle shaking to remove residual BNP from the plasma; 3) $1000 \mathrm{KIU}$ (kallikrein inhibition units) per $\mathrm{mL}$ of aprotinin from bovine lung (Sigma-Aldrich, MO, U.S.A.) was added into the BNP-depleted plasma to prepare base plasma; and 4) recombinant glycosylated proBNP (Hytest, Turku, Finland) and synthetic BNP-32 (Peptide Institute, Osaka, Japan) were added into the base plasma. The calibrators were prepared in two concentration levels of $\sim 40$ and $\sim 160 \mathrm{pg} / \mathrm{mL}$ (BNP-32 immunoreactivity), and the molar ratios of BNP-32 to glycosylated proBNP were adjusted to 50:50 and 25:75, respectively, which reflect proBNP ratios in clinical samples. In the same manner, other external BNP calibrators were prepared using only either BNP-32 or glycosylated proBNP

\subsection{Measurement of Pooled Plasma Samples and External BNP Calibrators}

Each of four to eight plasma samples as described in Section 2.2 in which the 
BNP concentrations were close were pooled, and 10 kinds of pooled plasma samples were prepared. These pooled plasma samples and the external BNP calibrators, which contained BNP-32 and/or glycosylated BNP as described above, were measured in duplicate by two commercial labs that use different chemiluminescent immunoassays (CLIA). In addition, these samples and the external BNP calibrators were measured using the MI02 Shionogi ${ }^{\circledast}$ BNP (MI02), a CLEIA automated analyzer that we previously developed [27]. The external BNP calibrators containing both BNP-32 and glycosylated BNP were also measured using the CLEIAs for proBNP and total BNP.

\subsection{Adjustment of Measured BNP Concentrations in Comparison with Measurement Results for Calibrators}

The same pooled plasma samples and the external BNP calibrators were also measured in duplicate using IRMA as a standard assay procedure. Measured concentrations of the external BNP calibrators using IRMA were defined as the assigned standard concentrations. Measured concentrations of the external BNP calibrators using each assay at a commercial lab or by the MI02 were compared with the assigned standard concentration, and the ratio of the assigned standard concentration to each concentration was determined as the adjustment factor. The initial concentrations of the pooled plasma samples measured using assays at commercial labs or by the MI02 were adjusted by multiplying by the adjustment factor. The detailed procedure for adjusting the concentration is shown in Table 1 .

\subsection{Data Analysis}

The agreement of measured BNP concentrations between each assay and the standard assay procedure (i.e. IRMA) was analyzed for every pair of assays by using a Passing-Bablok regression analysis with the Analyze-it for Microsoft Excel version 2.22. Coefficients of determination $\left(\mathrm{R}^{2}\right)$, $\mathrm{p}$-value and between-assay coefficient of variation (CV) were calculated with Microsoft Excel version 2016.

\section{Results and Discussion}

\subsection{Ratio of BNP-32 and proBNP in Clinical Samples}

We determined the ratios of BNP-32 and proBNP in clinical samples. The percentages of proBNP in plasma samples were analyzed using two CLEIAs for total $\mathrm{BNP}$ and specific for proBNP, respectively. We found that the percentage of

Table 1. Procedure for value adjustment using the external BNP calibrators.

\begin{tabular}{cc}
\hline Initial concentration (I.C.) of sample to be adjusted & Adjusted concentration \\
\hline Less than or equal to concentration a of the low level & Multiplication of the I.C. and the low level adjustment factor \\
Between concentrations ${ }^{\mathrm{a}}$ of the low and high levels & Multiplication of the I.C. and a factor proportionally calculated \\
Greater than or equal to concentration ${ }^{\mathrm{a}}$ of the high level & Multiplication of the I.C. and the high level adjustment factor
\end{tabular}

a: Concentrations of the external calibrators measured with the assay to be adjusted. 
proBNP increased according to the total BNP level up to $\sim 500 \mathrm{pg} / \mathrm{mL}$ (see Figure 2). This result is consistent with a previous study regarding the relationship between HF severity and proBNP abundance ratio [14].

\subsection{Determination of the Adjustment Factor According to Measurement Results of the External BNP Calibrators}

In a recent study, Semenov et al. suggested that glycosylated proBNP could serve as a common calibrator for BNP assays [28]. However, a common calibrator for BNP assays should contain both BNP-32 and glycosylated proBNP based on the ratios of BNP-32 and proBNP in clinical samples. This agrees with the fact that proBNP in circulation is O-glycosylated [17] [18] [19], especially in patients with severe HF, and is accompanied by a small amount of BNP-32 [29]. Moreover, we should recognize the utility and importance of currently measured BNP concentrations afforded by available instruments, which has huge clinical significance for diagnosis and treatment. Accordingly, suitable calibrators need to be prepared with the proper abundance ratios of BNP-32 and proBNP for various BNP levels. We thus compared the effect of value adjustment using external BNP calibrators containing BNP-32 alone, glycosylated BNP alone, and both BNP-32 and glycosylated BNP.

The IRMA reagent used in our current study was based on the SHIONORIA BNP [24], which was the first commercially available BNP assay kit in the world. Therefore, we settled on the IRMA method as the standard assay procedure to assign standard concentrations of the external BNP calibrators. Measurements of external BNP calibrators containing both BNP-32 and glycosylated BNP were performed by making use of IRMA to give "assigned concentrations" as shown in Table 2. We simultaneously examined calibrators containing BNP-32 alone
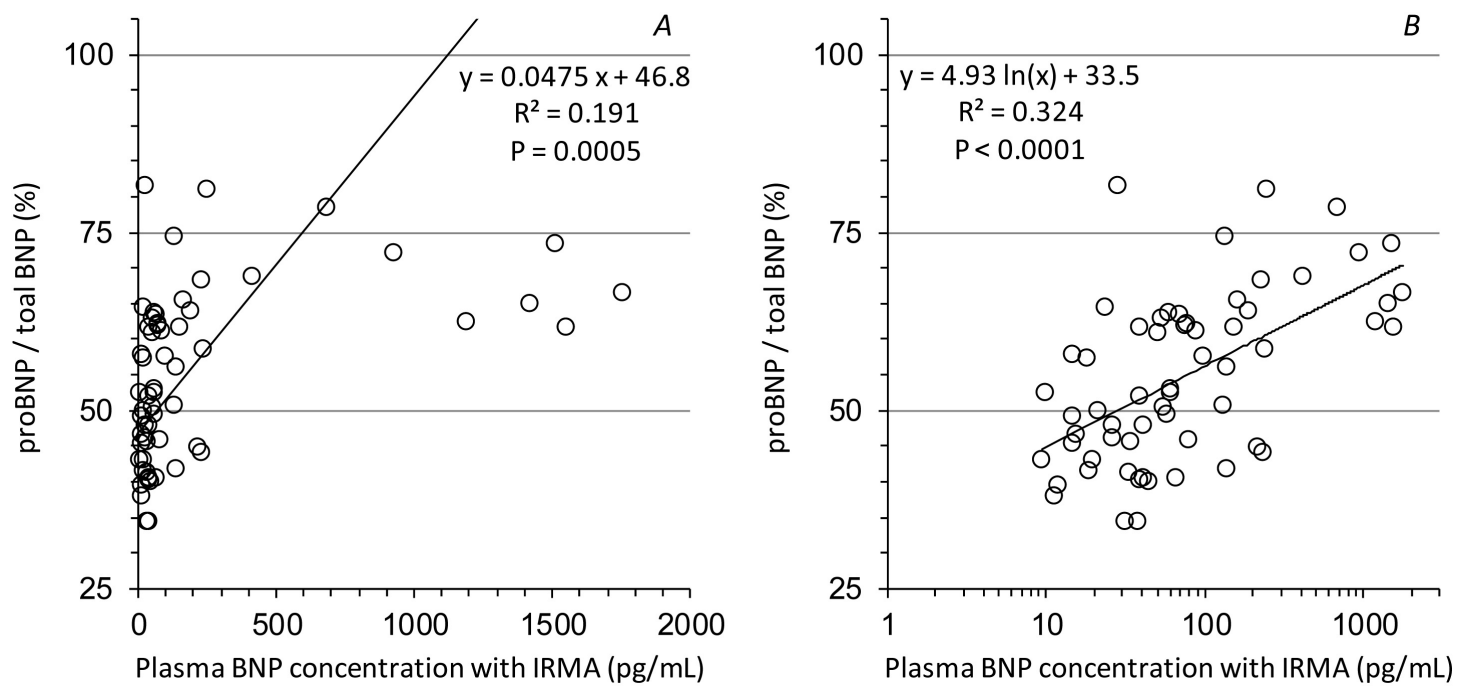

Figure 2. Relationship between BNP concentration and proBNP ratio. BNP concentrations of plasma samples (n $=60$ ) measured using IRMA are shown on the $X$ axis with a linear scale (A) and log scale $(B)$, and the percentages of proBNP to total BNP calculated from those measured concentrations using the CLEIAs for proBNP and total BNP are shown on the $Y$ axis. 
Table 2. Measured concentrations of external BNP calibrators containing BNP-32 and/or glycosylated proBNP (pg/mL) and determined adjustment factors (in parentheses). By comparing measurement values using the standard assay procedure (IRMA) (i.e. the assigned standard concentrations) and measurement values using each BNP assay, adjustment factors for each concentration level of each external calibrator were determined for each BNP assay. Percentages of proBNP to total BNP calculated from measured concentrations using the CLEIAs for proBNP and total BNP are shown below.

\begin{tabular}{|c|c|c|c|c|c|c|}
\hline \multirow[t]{2}{*}{ External BNP calibrator } & \multicolumn{2}{|c|}{$\begin{array}{l}\text { Mixture of BNP-32 and } \\
\text { glycosylated proBNP }\end{array}$} & \multicolumn{2}{|c|}{ BNP-32 only } & \multicolumn{2}{|c|}{$\begin{array}{c}\text { Glycosylated proBNP } \\
\text { only }\end{array}$} \\
\hline & Low level ${ }^{\mathrm{a}}$ & High level $^{\mathrm{b}}$ & Low level & High level & Low level & High leve \\
\hline $\begin{array}{c}\text { Assigned standard } \\
\text { concentration using the IRMA }\end{array}$ & 37.7 & 158.9 & 35.8 & 181.5 & 36.4 & 181.8 \\
\hline Commercial lab 1 & $\begin{array}{c}42.9 \\
(0.88)\end{array}$ & $\begin{array}{l}156.0 \\
(1.02)\end{array}$ & $\begin{array}{c}53.6 \\
(0.67)\end{array}$ & $\begin{array}{l}238.8 \\
(0.76)\end{array}$ & $\begin{array}{c}41.6 \\
(0.88)\end{array}$ & $\begin{array}{l}164.6 \\
(1.10)\end{array}$ \\
\hline Commercial lab 2 & $\begin{array}{c}23.6 \\
(1.60)\end{array}$ & $\begin{array}{l}103.3 \\
(1.54)\end{array}$ & $\begin{array}{c}22.9 \\
(1.56)\end{array}$ & $\begin{array}{c}85.2 \\
(2.13)\end{array}$ & $\begin{array}{c}26.6 \\
(1.37)\end{array}$ & $\begin{array}{l}126.8 \\
(1.43)\end{array}$ \\
\hline MI02 Shionogi ${ }^{\circledR}$ BNP & $\begin{array}{c}28.0 \\
(1.35)\end{array}$ & $\begin{array}{l}138.1 \\
(1.15)\end{array}$ & $\begin{array}{c}37.6 \\
(0.95)\end{array}$ & $\begin{array}{l}187.8 \\
(0.97)\end{array}$ & $\begin{array}{c}36.6 \\
(0.99)\end{array}$ & $\begin{array}{l}197.5 \\
(0.92)\end{array}$ \\
\hline $\begin{array}{c}\text { Percentage of proBNP to total } \\
\text { BNP }(\%)\end{array}$ & 62.2 & 80.3 & n.t. & n.t. & n.t. & n.t. \\
\hline
\end{tabular}

n.t.: Not tested; a: Ratio of the BNP-32 and the glycosylated proBNP is 50:50; b: Ratio of the BNP-32 and the glycosylated proBNP is 25:75.

and glycosylated proBNP alone. Subsequently, we also measured these external BNP calibrators at commercial labs or by using the MI02 method to afford the measured concentrations as shown in Table 2.

Measured percentages of proBNP to total BNP for the external BNP calibrators containing both BNP-32 and glycosylated BNP are also shown in Table 2. In addition, by comparing the assigned standard values and measurement values using assays at commercial labs or the MI02, adjustment factors were determined for each concentration level of each external BNP calibrator (see Table 2). An example of a calculation of the adjustment factor for samples between low and high concentration level calibrators is shown in Figure 3.

\subsection{Effect of Value Adjustments Using the External BNP Calibrators}

Each initial concentration of the pooled plasma sample was adjusted according to the determined adjustment factors for each level of each external BNP calibrator for each assay. And the consistency of each measured concentration using each assay to the concentration using the standard assay procedure (IRMA) was evaluated for the initial concentrations and the adjusted concentrations. Results of the adjustments according to the determined adjustment factors for the external BNP calibrators containing both BNP-32 and glycosylated proBNP are shown in Figure 4. Though there were comparative differences between the initial concentrations of each assay and the concentrations using the standard assay procedure (IRMA), the differences became smaller after the adjustment. However, 

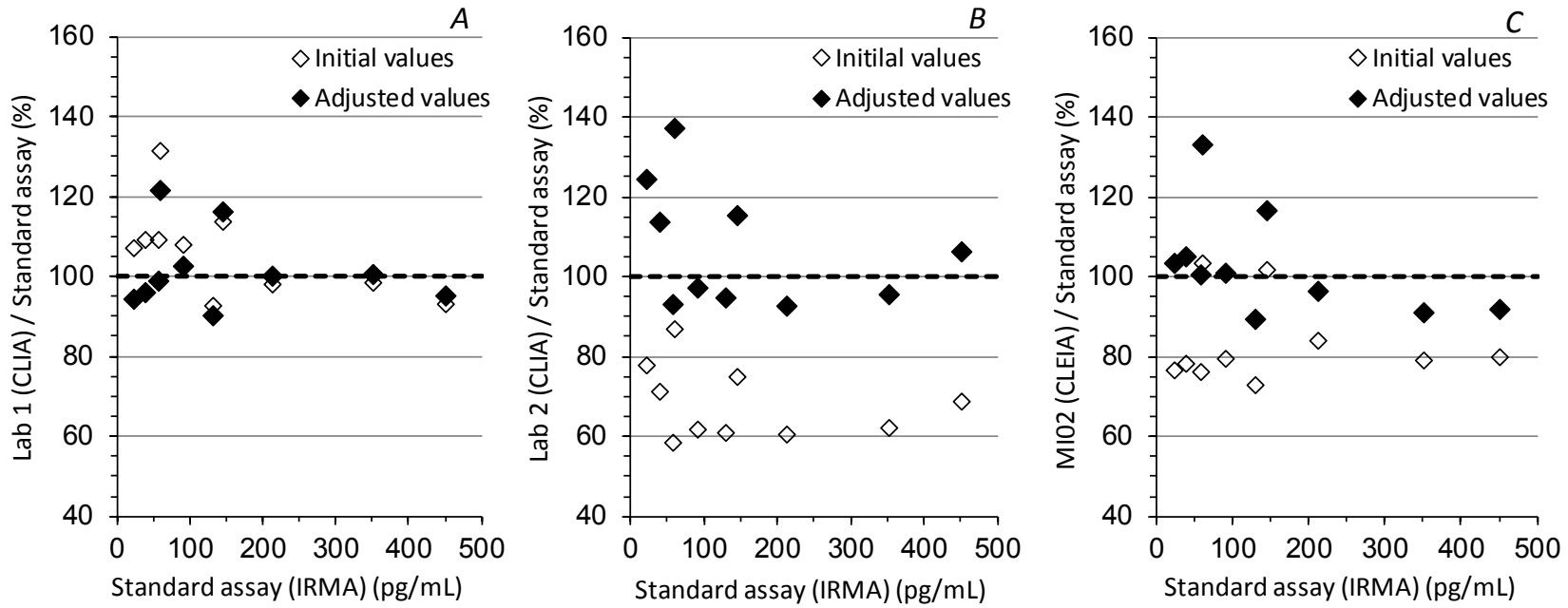

Figure 4. Adjustment of measured concentrations of the assays at commercial labs (A and B) and the MI02 Shionogi (C) according to measured concentrations of the external BNP calibrators. BNP concentrations using the standard assay procedure (IRMA) are shown on the $X$ axis, and the percentages of BNP concentrations of pooled plasma samples to each corresponding measured concentration using the standard assay procedure (IRMA) are shown on the $Y$ axis, with open symbols for initial concentrations and closed symbols for adjusted concentrations.

using the determined adjustment factors for external BNP calibrators containing only either BNP-32 or glycosylated proBNP did not further reduce the differences, or rather made the differences worse for the calibrators containing only BNP-32 (data not shown).

Correlations of measured concentrations of the pooled plasma samples using each assay to the concentrations using the standard assay procedure (IRMA) for the initial concentrations and the adjusted concentrations for each external BNP calibrator are shown in Table 3. Similar to the consistency of measured concentrations, 
Table 3. Correlation of measured concentrations between various BNP assays and the standard assay procedure (IRMA). Measured BNP concentrations of the pooled plasma samples using commercial labs or the MI02 Shionogi ${ }^{\circledast}$ BNP were adjusted according to the determined factors using the external BNP calibrators containing BNP-32 and/or glycosylated proBNP, and correlations were evaluated before and after the value adjustment. The Passing-Bablok regression analysis ( $x$ : standard assay procedure (IRMA)) and coefficient of determination $\left(\mathrm{R}^{2}\right)$ along with p-value are presented in table cells.

\begin{tabular}{cccc}
\hline Assay & Commercial lab 1 (CLIA) & Commercial lab 2 (CLIA) & MI02 Shionogi BNP (CLEIA) \\
\hline Initial concentrations & $y=0.955 x+6.65$ & $y=0.628 x+1.19$ & $y=0.799 x-0.81$ \\
& $\left(\mathrm{R}^{2}=0.994, \mathrm{P}<0.0001\right)$ & $\left(\mathrm{R}^{2}=0.989, \mathrm{P}<0.0001\right)$ & $\left(\mathrm{R}^{2}=0.990, \mathrm{P}<0.0001\right)$ \\
Adjusted concentrations & $y=1.005 x-0.96$ & $y=0.961 x+3.67$ & $y=0.911 x+5.49$ \\
$\left(\right.$ Calibrators contain both $\left.{ }^{\mathrm{a}}\right)$ & $\left(\mathrm{R}^{2}=0.994, \mathrm{P}<0.0001\right)$ & $\left(\mathrm{R}^{2}=0.988, \mathrm{P}<0.0001\right)$ & $\left(\mathrm{R}^{2}=0.991, \mathrm{P}<0.0001\right)$ \\
Adjusted concentrations & $y=0.733 x+0.03$ & $y=1.392 x-13.25$ & $y=0.774 x-1.17$ \\
$($ Calibrators contain only BNP-32) & $\left(\mathrm{R}^{2}=0.995, \mathrm{P}<0.0001\right)$ & $\left(\mathrm{R}^{2}=0.989, \mathrm{P}<0.0001\right)$ & $\left(\mathrm{R}^{2}=0.990, \mathrm{P}<0.0001\right)$ \\
Adjusted concentrations & $y=1.089 x-2.97$ & $y=0.899 x-0.43$ & $y=0.732 x+1.30$ \\
$($ Calibrators contain only glyc proBNP) & $\left(\mathrm{R}^{2}=0.993, \mathrm{P}<0.0001\right)$ & $\left(\mathrm{R}^{2}=0.989, \mathrm{P}<0.0001\right)$ & $\left(\mathrm{R}^{2}=0.989, \mathrm{P}<0.0001\right)$ \\
\hline
\end{tabular}

a: BNP-32 and glycosylated proBNP.

correlations were improved after concentration adjustments based on the external BNP calibrators containing both BNP-32 and glycosylated proBNP.

Between-assay CVs for initial concentrations and the adjusted concentrations of the pooled plasma samples are shown in Table 4. We observed a significant reduction of the $\mathrm{CV}$ from $22.8 \%$ for the initial concentrations to $5.6 \%$ for the adjusted concentrations based on the external BNP calibrators containing both BNP-32 and glycosylated proBNP.

The present study indicates that value adjustment using the external BNP calibrators containing both BNP-32 and glycosylated proBNP at different ratios by concentration level enables good comparability of measured BNP concentrations among different assays. Even though cross-reactivities to glycosylated proBNP are different among assays [23], using our new BNP calibrators, which reflect the abundance ratio of proBNP and its glycosylated molecular form in clinical samples, could cancel out such difference.

In this study, we treated the new BNP calibrators as external calibrators to adjust the measured concentrations, the procedure for which is somewhat complicated. To resolve this problem, it is possible to use the new BNP calibrators as internal calibrators of each BNP assay by preparing more calibrator levels, 5 for instance. Moreover, these new BNP calibrators can be used for quality control purposes and in lyophilized form to improve handling and stability.

It is critical to consider the procedure to assign concentrations to the new BNP calibrators. In this study, we deemed that IRMA, which is based on the SHIONORIA BNP or the first commercially available BNP assay kit in the world, was a suitable standard assay procedure to determine the concentrations of the calibrators. In the same manner, accepted reference concentrations should be assigned using IRMA based on the SHIONORIA BNP. A problem has been that measured BNP concentrations are not comparable among different immunoassays, especially between the SHIONORIA BNP and the Biosite Triage BNP or the Abbott AxSYM System [30] [31]. The variety of antibodies and calibrator 
Table 4. Between-assay CVs for initial concentrations and adjusted concentrations according to different external BNP calibrators. The equivalence of four assays (two assays at commercial labs, the MI02 Shionogi ${ }^{\oplus}$ BNP, and the IRMA) was evaluated as the mean between-assay CV (\%) for measured concentrations of the pooled plasma samples and adjusted according to the determined factors using the external BNP calibrators containing BNP-32 and/or glycosylated proBNP.

\begin{tabular}{cc}
\hline External calibrator used for value adjustment & Mean between-assay CV (\%) (SD) \\
\hline None (initial concentration) & $22.8(4.6)$ \\
Both BNP-32 and glycosylated proBNP & $5.6(3.9)$ \\
BNP-32 only & $31.9(7.3)$ \\
Glycosylated proBNP only & $15.5(2.6)$ \\
\hline
\end{tabular}

materials used in the assays might be the cause of these differences. Since the Biosite and Abbott assays were launched in the US and Europe, comparability with BNP measurements in Japan and other countries was lost. Using the new BNP calibrators as common calibrators and assigning accepted reference concentrations by IRMA would harmonize BNP assay results throughout the world.

\section{Conclusion}

Circulating forms of BNP in clinical samples are diverse; however, in the current study, the ratios of proBNP (mainly glycosylated proBNP) to total BNP showed an increasing trend by BNP concentration. The new BNP calibrators we designed to contain both BNP-32 and glycosylated proBNP and reflect the ratio of proBNP in clinical samples by increasing concentration level. Superior comparability of measured BNP concentrations among assays was observed using the new BNP calibrators. These new BNP calibrators could be an international reference material that harmonizes $\mathrm{BNP}$ assay results to enhance diagnostic and therapeutic efficacy.

\section{Acknowledgements}

We thank Yuji Kawahara and Naoko Ogawa for their excellent technical assistance.

\section{Conflicts of Interest}

The authors declare no conflicts of interest regarding the publication of this paper.

\section{References}

[1] Sudoh, T., Maekawa, K., Kojima, M., Minamino, N., Kangawa, K. and Matsuo, H. (1989) Cloning and Sequence Analysis of cDNA Encoding a Precursor for Human Brain Natriuretic Peptide. Biochemical and Biophysical Research Communications, 159, 1427-1434. https://doi.org/10.1016/0006-291X(89)92269-9

[2] Mukoyama, M., Nakao, K., Saito, Y., Ogawa, Y., Hosoda, K., Suga, S., Shirakami, G., Jougasaki, M. and Imura, H. (1990) Human Brain Natriuretic Peptide, a Novel Car- 
diac Hormone. The Lancet, 335, 801-802.

https://doi.org/10.1016/0140-6736(90)90925-U

[3] Mukoyama, M., Nakao, K., Saito, Y., Ogawa, Y., Hosoda, K., Suga, S., Shirakami, G., Jougasaki, M. and Imura, H. (1990) Increased Human Brain Natriuretic Peptide in Congestive Heart Failure. The New England Journal of Medicine, 323, 757-758. https://doi.org/10.1056/NEJM199009133231114

[4] Nakata, K., Komukai, K., Yoshii, Y., Miyanaga, S., Kubota, T., Kosuga, T., Suzuki, K., Yamada, T., Yoshida, J., Kimura, H., Takagi, M., Shimizu, M. and Yoshimura, M. (2015) The Optimal Cut-Off Value of Plasma BNP to Differentiate Heart Failure in the Emergency Department in Japanese Patients with Dyspnea. Internal Medicine, 54, 2975-2980.

[5] Nakamura, M., Ishibashi, Y., Tanaka, F., Omama, S., Onoda, T., Takahashi, T., Takahashi, S., Tanno, K., Ohsawa, M., Sakata, K., Koshiyama, M., Ogasawara, K. and Okayama, A. (2018) Ability of B-Type Natriuretic Peptide Testing to Predict Cardioembolic Stroke in the General Population-Comparisons With C-Reactive Protein and Urinary Albumin. Circulation Journal, 82, 1017-1025.

[6] Ponikowski, P., Voors, A.V., Anker, S.D., Bueno, H., Cleland, J.G.F., Coats, A.J.S., Falk, V., González-Juanatey, J.R., Harjola, V., Jankowska, E.A., Jessup, M., Linde, C., Nihoyannopoulos, P., Parissis, J.T., Pieske, B., Riley, J.P., Rosano, G.M.C., Ruilope, L.M., Ruschitzka, F., Rutten, F.H. and Meer, P. (2016) 2016 ESC Guidelines for the Diagnosis and Treatment of Acute and Chronic Heart Failure. European Heart Journal, 37, 2129-2200. https://doi.org/10.1093/eurheartj/ehw128

[7] Yancy, C.W., Jessup, M., Bozkurt, B., Butler, J., Casey Jr., D.E., Colvin, M.M., Drazner, M.H., Filippatos, G.S., Fonarow, G.C., Givertz, M.M., Hollenberg, S.M., Lindenfeld, J., Masoudi, F.A., McBride, P.E., Peterson, P.N., Stevenson, L.W. and Westlake, C. (2017) 2017 ACC/AHA/HFSA Focused Update of the 2013 ACCF/AHA Guideline for the Management of Heart Failure. Circulation, 136, e137-e161.

[8] Tateyama, H., Hino, J., Minamino, N., Sakaki, K., Ogihara, T. and Matsuo, H. (1992) Concentration and Molecular Form of Human Nartiuretic Peptide in Plasma. Biochemical and Biophysical Research Communications, 185, 760-767. https://doi.org/10.1016/0006-291X(92)91691-I

[9] Yandle, T.G., Richards, A.M, Gilbert, A., Fisher, S., Holmes, S. and Espiner, E.A. (1993) Assay of Brain Natriuretic Peptide (BNP) in Human Plasma: Evidence for High Molecular Weight BNP as a Major Plasma Component in Heart Failure. The Journal of Clinical Endocrinology \& Metabolism, 76, 832-838. https://doi.org/10.1210/jcem.76.4.8473392

[10] Shimizu, H., Masuta, K., Aono, K., Asada, H., Sasakura, K., Tamaki, M., Sugita, K. and Yamada, K. (2002) Molecular Forms of Human Brain Natriuretic Peptide in Plasma. Clinica Chimica Acta, 316, 129-135. https://doi.org/10.1016/S0009-8981(01)00745-8

[11] Giuliani, I., Rieunier, F., Larue. C., Delagneau, J.F., Granier, C., Pau, B., Ferrière, M., Saussine, M., Cristol, J.P., Dupuy, A.M., Merigeon, E., Merle, D. and Villard, S. (2006) Assay for Intact B-Type Natriuretic Peptide Prohormone in Blood. Clinical Chemistry, 52, 1054-1061. https://doi.org/10.1373/clinchem.2005.061770

[12] Seferian, K.R., Tamm, N.N., Semenov, A.G., Mukharyamova, K.S., Tolstaya, A.A., Koshkina, E.V., Kara, A.N., Krasnoselsky, M.I., Apple, F.S., Esakova, Y.V., Filatov, V.L. and Katrukha, A.G. (2007) The Brain Natriuretic Peptide (BNP) Precursor Is the Major Immunoreactive Form of BNP in Patient with Heart Failure. Clinical Chemistry, 53, 866-873. https://doi.org/10.1373/clinchem.2006.076141

[13] Tamm, N.N., Seferian, K.R., Semenov, A.G., Mukharyamova, K.S., Koshkina, E.V., 
Krasnoselsky, M.I., Postnikov, A.B., Serbryanaya, D.V., Apple, F.S., Murakami, M.M. and Katrukha, A.G. (2008) Novel Immunoassay for Quantification of Brain Natriuretic Peptide and Its Precursor in Human Blood. Clinical Chemistry, 54, 1511-1518. https://doi.org/10.1373/clinchem.2007.100545

[14] Nishikimi, T., Minamino, N., Ikeda, M., Takeda, Y., Tadokoro, K., Shibasaki, I., Fukuda, H., Horiuchi, Y., Oikawa, S., Ieiri, T., Matsubara, M. and Ishimitsu, T. (2010) Diversity of Molecular Forms of Plasma Brain Natriuretic Peptide in Heart Failure-Different proBNP-108 to BNP-32 Ratios in Atrial and Ventricular Overload. Heart, 96, 432-439. https://doi.org/10.1136/hrt.2009.178392

[15] Schellenberger, U., O'Rear, J., Guzzetta, A., Jue, R.A., Protter, A.A. and Pollitt, N.S. (2006) The Precursor to B-Type Natriuretic Peptide Is an O-Linked Glycoprotein. Archives of Biochemistry and Biophysics, 451, 160-166.

https://doi.org/10.1016/j.abb.2006.03.028

[16] Halfinger, B., Hammerer-Lercher, A., Amplatz, B., Sarg, B., Kremser, L. and Lindner, H.H. (2017) Unraveling the Molecular Complexity of O-Glycosylated Endogenous (N-Terminal) pro-B-Type Natriuretic Peptide Forms in Blood Plasma of Patients with Severe Heart Failure. Clinical Chemistry, 63, 359-368. https://doi.org/10.1373/clinchem.2016.265397

[17] Semenov, A.G., Postnikov, A.B., Tamm, N.N., Seferian, K.R., Karpova, N.S., Bloshchitsyna, M.N., Koshkina, E.V., Krasnoselsky, M.I., Serebryanaya, D.V. and Katrukha, A.G. (2009) Processing of Pro-Brain Natriuretic Peptide Is Suppressed by O-Glycosylation in the Region Close to the Cleavage Site. Clinical Chemistry, 55, 489-498. https://doi.org/10.1373/clinchem.2008.113373

[18] Semenov, A.G., Tamm, N.N., Seferian, K.R., Postnikov, A.B., Karpova, N.S., Serebryanaya, D.V., Koshkina, E.V., Krasnoselsky, M.I. and Katrukha, A.G. (2010) Processing of pro-B-Type Natriuretic Peptide: Furin and Corin as Candidate Convertases. Clinical Chemistry, 56, 1166-1176.

https://doi.org/10.1373/clinchem.2010.143883

[19] Nishikimi, T., Nakagawa, Y., Minamino, N., Ikeda, M., Tabei, K., Fujishima, A., Takayama, K., Akimoto, K., Yamada, C., Nakao, K., Minami, T., Kuwabara, Y., Kinoshita, H., Tsutamoto, T., Ishimitsu, T., Kangawa, K., Kuwahara, K. and Nakao, K. (2015) Pro-B-Type Natriuretic Peptide Is Cleaved Intracellularly: Impact of Distance between O-Glycosylation and Cleavage Sites. The American Journal of Physiology-Regulatory, Integrative and Comparative Physiology, 309, R639-R649. https://doi.org/10.1152/ajpregu.00074.2015

[20] Nishikimi, T., Minamino, N., Horii, K. and Matsuoka, H. (2007) Do Commercially Available Kits for B-Type Natriuretic Peptide Measure Pro-BNP1-108, as Well as BNP1-32? Hypertension, 50, e163. https://doi.org/10.1161/HYPERTENSIONAHA.107.098350

[21] Luckenbill, K.N, Christenson, R.H., Jaffe, A.S., Mair, J., Ordonez-Llanos, J., Pagani, F., Tate, J., Wu, A.H.B, Ler, R. and Apple, F.S. (2008) Cross-Reactivity of BNP, NT-ProBNP and ProBNP in Commercial BNP and NT-ProBNP Assays: Preliminary Observations from the IFCC Committee for Standardization of Markers of Cardiac Damage. Clinical Chemistry, 54, 619-620. https://doi.org/10.1373/clinchem.2007.097998

[22] Cauliez, B, Santons, H., Bauer, F., Basuyau, J.P., Nadolny, A., Galpy, G. and Lavoinne, A. (2012) Cross-Reactivity with Endogenous ProBNP from Heart Failure Patients for Three Commercial BNP Immunoassays. Clinica Chimica Acta, 413, 337-338. https://doi.org/10.1016/j.cca.2011.09.022

[23] Saenger, A.K., Rodriguez-Fraga, O., Ler, R., Ordonez-Llanos, J., Jaffe, A.S., Goetze, 
J.P. and Apple, F.S. (2017) Specificity of B-Type Natriuretic Peptide Assays: Cross-Reactivity with Different BNP, NT-proBNP, and proBNP Peptides. Clinical Chemistry, 63, 351-358. https://doi.org/10.1373/clinchem.2016.263749

[24] Kono, M., Yamauchi, A., Tsuji, T., Misaki, A., Igano, K., Ueki, K., Fujishima, M., Ueda, A., Inouye, K., Nakao, K. and Imura, H. (1993) An Immunoradiometric Assay for Brain Natriuretic Peptide in Human Plasma. The Japanese Journal of Nuclear Medicine Technology, 13, 2-7.

[25] Tsuju, T., Imagawa, K., Masuda, H., Haraikawa, M., Shibata, K., Kono, M., Inouye, K. and Uchida, H. (1994) Stabilization of Human Brain Natriuretic Peptide in Blood Samples. Clinical Chemistry, 40, 672-673.

[26] Nishikimi, T., Okamoto, H., Nakamura, M., Ogawa, N., Horii, K., Nagata, K., Nakagawa, Y., Kinoshita, H., Yamada, C., Nakao, K., Minami, T., Kuwabara, Y., Kuwahara, K., Masuda, I., Kangawa, K., Minamino, N. and Nakao, K. (2013) Direct Immunochemiluminescent Assay for proBNP and Total BNP in Human Plasma proBNP and Total BNP Levels in Normal and Heart Failure. PLOS ONE, 8, e53233. https://doi.org/10.1371/journal.pone.0053233

[27] Shimosako, K., Takahashi, A., Saitou, T., Tanaka, H., Kaneshige, T. and Futana, T. (2005) Evaluation of Automated Chemiluminescent Immunoassay Analyzer Exclusive Kit "MI02 Shionogi BNP". Journal of Pharmaceutical Science and Technology, Japan, 53, 355-360.

[28] Semenov, A.G., Tamm, N.N., Apple, F.S., Schulz, K.M., Love, S.A., Ler, R., Feygina, E.E. and Katrukha, A.G. (2017) Searching for a BNP Standard: Glycosylated proBNP as a Common Calibrator Enables Improved Comparability of Commercial BNP Immunoassays. Clinical Biochemistry, 50, 181-185. https://doi.org/10.1016/j.clinbiochem.2016.11.003

[29] Hammerer-Lercher, A., Halfinger, B., Sarg, B., Mair, I.J., Puschendorf, B., Griesmacher, A., Guzman, N.A. and Lindner, H.H. (2008) Analysis of Circulating Forms of proBNP and NT-proBNP in Patients with Severe Heart Failure. Clinical Chemistry, 54, 858-865. https://doi.org/10.1373/clinchem.2007.090266

[30] Fischer, Y., Filzmaier, K., Stiegler, H., Graf, J., Fuhs, S., Franke, A., Janssens, U. and Gressner, A.M. (2001) Evaluation of a New, Rapid Bedside Test for Quantitative Determination of B-Type Natriuretic Peptide. Clinical Chemistry, 47, 591-594.

[31] Clerico, A., Prontera, C., Emdin, M., Passino, C., Storti, S., Poletti, R., Zyw, L. and Zucchelli. G.C. (2005) Analytical Performance and Diagnostic Accuracy of Immunometric Assays for the Measurement of Plasma B-Type Natriuretic Peptide (BNP) and N-Terminal proBNP. Clinical Chemistry, 51, 445-447.

https://doi.org/10.1373/clinchem.2004.038281 